\title{
Relationship of age with periodontal diseases for males and females in Bangladesh; A hospital registry based cross-sectional observational study.

\author{
Md Huzzatul Islam Khan ${ }^{1 *}$, Ruksana Islam Sadia², Sumaia Akter Ema ${ }^{3}$, Nayna Binte Shahabuddin ${ }^{4}$, Rifat Rahman ${ }^{5}$, Md. Ashif Iqbal ${ }^{6}$
}

\section{AFFILIATION:}

1. Md Huzzatul Islam Khan, BDS

Lecturer of Periodontology \& Oral Pathology

Update Dental College \& Hospital

2. Ruksana Islam Sadia

Final Year BDS Student,

Update Dental College \& Hospital

3. Sumaia Akter Ema,

Final Year BDS Student,

Update Dental College \& Hospital

4. Nayna Binte Shahabuddin, BDS

Lecturer of Periodontology \& Oral Pathology

Update Dental College \& Hospital

5. Rifat Rahman, BDS, MPH, MSc

Senior Lecturer of Oral Medicine, Update Dental College \& Hospital

6. Md. Ashif Iqbal, BDS, DDS

Associate Professor \& Head of Periodontology \& Oral Pathology

Update Dental College \& Hospital

\section{Article info.}

Received: $29^{\text {th }}$ March, 2019

Accepted: $15^{\text {th }}$ August, 2019

Volume: 9, Issue-2 October, 2019

DOI: https://doi.org/10.3329/updcj.v9i2.43733

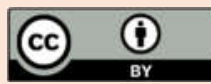

(C) Authors retain copyright and grant the journal right of first publication with the work simultaneously licensed under Creative Commons Attribution License CC - BY 4.0 that allows others to share the work with an acknowledgment of the work's authorship and initial publication in this journal.

https://creativecommons.org/licenses/by/4.0/

Publisher: Update Dental College, Dhaka, Bangladesh

Web: www.updatedentalcollege.edu.bd

E-mail: updcj@hotmail.com

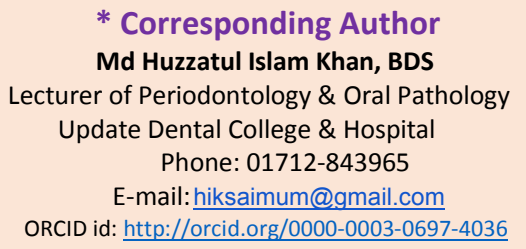

\section{Citation}

Md Huzzatul Islam Khan, Ruksana Islam Sadia, Sumaia Akter Ema, Nayna Binte Shahabuddin , Rifat Rahman, Md. Ashif Iqbal. Relationship of age with periodontal diseases for males and females in Bangladesh; A hospital registry based cross-sectional observational study. Update Dental College Journal. 2019 October; 9(2): 13-16

DOI: https://doi.org/10.3329/updcj.v9i2.43733

\begin{abstract}
Periodontal diseases are the most commonly occurred diseases in the oral cavity with a widespread distribution around the globe. Variation in periodontal tissues associated with the aging and gender of the patient. The aim of this study was to determine relationship of age with periodontal diseases for males and females in Bangladeshi people. This study was conducted on 1837 patients visiting Department of Periodontology \& Oral Medicine, Update Dental College \& Hospital, from January 2017 to December 2018 (2 years) through a non-interventional cross-sectional method using descriptive and analytical statistics. Periodontal disease is the dependent variable of this study; patient age and gender serve as the independent variable. Total $37.5 \%$ patients suffered from periodontitis and $62.5 \%$ suffered from gingivitis. Up to 48 years of age the prevalence of gingivitis was higher (70.64\%) but periodontitis was more common (64.76\%) in case of people over 48 years age. There is a significant $(p<0.05)$ correlation between age and periodontal diseases exists in this study but no significant $(p>0.05)$ correlation identified with gender. Distribution of periodontal diseases shows similar pattern between female (gingivitis $=62.61 \%$, periodontitis $=37.53 \%$ ) and male (gingivitis $=62.47 \%$, periodontitis $=37.39 \%$ ). Periodontal diseases are primarily correlating with the age but gender may not be associated. The most prevalent form of periodontal disease is gingivitis.
\end{abstract}

KEY WORDS: Periodontal disease, Periodontal diseases with gender distribution, Age \& periodontal disease.

\section{INTRODUCTION}

Periodontal disease is termed as infection in the periodontal tissuesi. It is classified into gingival disease, chronic periodontitis, aggressive periodontitis, periodontitis as a manifestation of systemic disease, necrotizing periodontal disease, periodontal abscess, periodontal disease associated to endodontic lesion and developmental/acquired deformities and condition ${ }^{\mathrm{ii}}$. Multiple studies have concluded that periodontal diseases occur due to multi-factorial etiologyiii. One of the factors that influence the prevalence of periodontal disease is age. With the increase of age the severity and extent of periodontal diseases increase $e^{\text {iv. }}$. The alterations in the periodontal structure related to the patient age also helps in considering age as a periodontal diseases risk factor ${ }^{v}$. Some studies showed significant gender predilection in periodontal disease prevalence where men are more affected than female ${ }^{\text {vi }}$. Oral hygiene unawareness tends to be the main cause

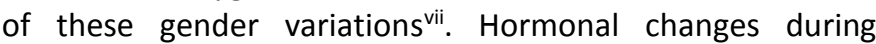
menstrual cycle may cause appearance of periodontal disease in female at certain period of time in females ${ }^{\text {viii. The general }}$ concept of an epidemiology study it to gain information to promote, protect and restore health based on evidence ${ }^{\text {ix }}$. However, since very limited numbers of epidemiological studies have been performed to see the prevalence of periodontal diseases in Bangladesh, this study aims to serve as a source of consideration for taking further actions to tackle 
the disease.

METHODS \& MATERIALS:

This study was conducted at the Department of Periodontology \& Oral Medicine, Update Dental College \& Hospital, through a non-interventional cross-sectional method using descriptive and analytical statistics. Total 1837 patients visiting department of Periodontology from January 2017 to December 2018 ( 2 years) used as a sample, with total sampling as the sampling method. Periodontal disease is the dependent variable of this study; patient age and gender serve as the independent variable.

Periodontal disease is classified based on American Academy of Periodontology that includes gingival disease, chronic periodontitis, aggressive periodontitis, and periodontitis as a manifestation of systemic disease.

Gingival disease or gingivitis is an inflammatory condition of gingival tissues and periodontitis refers to the inflammation of periodontal ligament and alveolar bone resulting in attachment loss. Apical migration of junctional epithelium from its biological location, cemento-enamel junction (CEJ), is known as $A L$ and was measured in millimeters from CEJ to base of the periodontal pocket by William's periodontal probe in this study. Gingivitis was identified and diagnosed using Modified gingival index (MGI) and absence of AL. Presence of $\mathrm{AL}$, gingival recession, tooth mobility and furcation involvement also examined during routine examination at first visit. Though, only AL was fixed to identify Periodontitis in this study.

This study began with the collection of dental records from January 2017 to December 2018, which were later selected from based on the criteria that the medical records must consist of information on patient age, gender and periodontal diagnosis. The 1,837 selected dental records were then recorded and processed by Microsoft Excel. For bivariate analysis, the variables of periodontal disease were ranked in two categories namely gingivitis and periodontitis, including chronic periodontitis, aggressive periodontitis and periodontitis as a manifestation of systemic disease. Data analysis was done by IBM SPSS Statistics version 21.0.

\section{RESULTS}

Among 1837 patients reported, 54.2\% were male and $45.8 \%$ were female (Figure-01). The mean age was 36.82 years and ranged from $10-85$ years (Table-01). Out of the total patients diagnosed, $37.5 \%$ suffered from periodontitis and $62.5 \%$ suffered from gingivitis (Figure-02). There is a significant $(p<0.05)$ correlation between age and periodontal diseases exists in this study (Table-2). Up to 48 years of age the prevalence of gingivitis was higher $(70.64 \%)$ but periodontitis was more common (64.76\%) in case of people over 48 years age (Figure-3). Distribution of periodontal diseases shows similar pattern between female (gingivitis=62.61\%, periodontitis $=37.53 \%$ ) and male (gingivitis $=62.47 \%$, periodontitis=37.39\%) (Figure-04).
Figure 1: Gender Distribution of total sample.

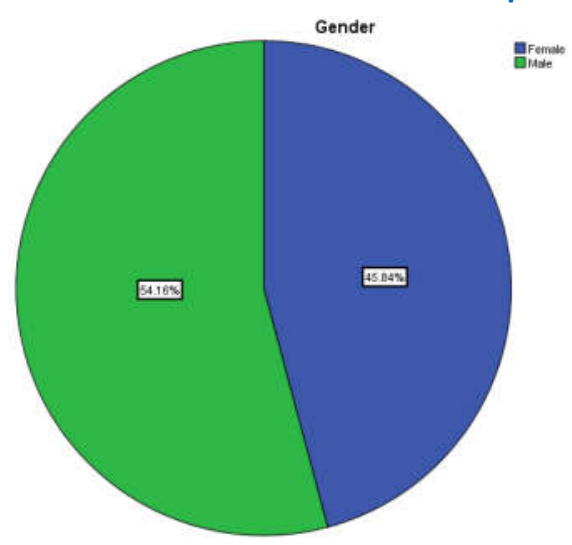

Table 1: Age distribution of total sample

\begin{tabular}{|c|c|c|c|c|c|}
\hline \multicolumn{6}{|c|}{ Age Distribution } \\
\hline & $\mathrm{N}$ & $\begin{array}{l}\text { Min } \\
\text { imu }\end{array}$ & $\begin{array}{l}\text { Maxi } \\
\text { mum }\end{array}$ & Mean & $\begin{array}{c}\text { Std. } \\
\text { Deviati } \\
\text { on }\end{array}$ \\
\hline Age & 1837 & 10 & 85 & 36.82 & 13.557 \\
\hline Valid N (listwise) & 1837 & & & & \\
\hline
\end{tabular}

Figure 2: Distribution of Periodontal Diseases

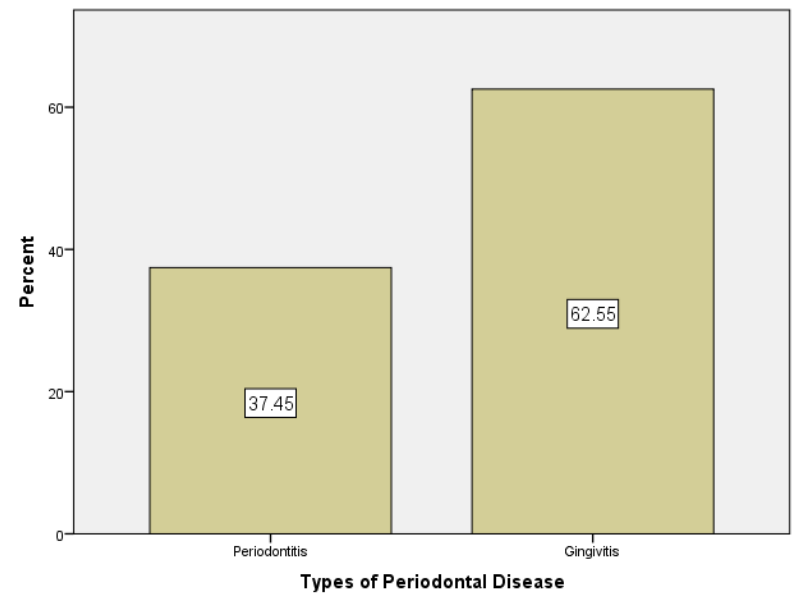

Table 2 Spearman's rho test

\begin{tabular}{|c|c|c|c|c|}
\hline & & & Age & Diagnosis \\
\hline \multirow[t]{6}{*}{$\begin{array}{l}\text { Spearma } \\
\text { n's rho }\end{array}$} & \multirow[t]{3}{*}{ Age } & $\begin{array}{l}\text { Correlation } \\
\text { Coefficient }\end{array}$ & 1.000 & $-.354^{* *}$ \\
\hline & & Sig. (2-tailed) & . & .000 \\
\hline & & $\mathrm{N}$ & 1837 & 1837 \\
\hline & \multirow{3}{*}{$\begin{array}{l}\text { Periodon } \\
\text { tal } \\
\text { Disease }\end{array}$} & $\begin{array}{l}\text { Correlation } \\
\text { Coefficient }\end{array}$ & $-.354^{* *}$ & 1.000 \\
\hline & & Sig. (2-tailed) & .000 & . \\
\hline & & $\mathrm{N}$ & 1837 & 1837 \\
\hline
\end{tabular}

Website: https://www.banglajol.info/index.php/UpDCJ 
Figure 3: Distribution of periodontal diseases in different ages.

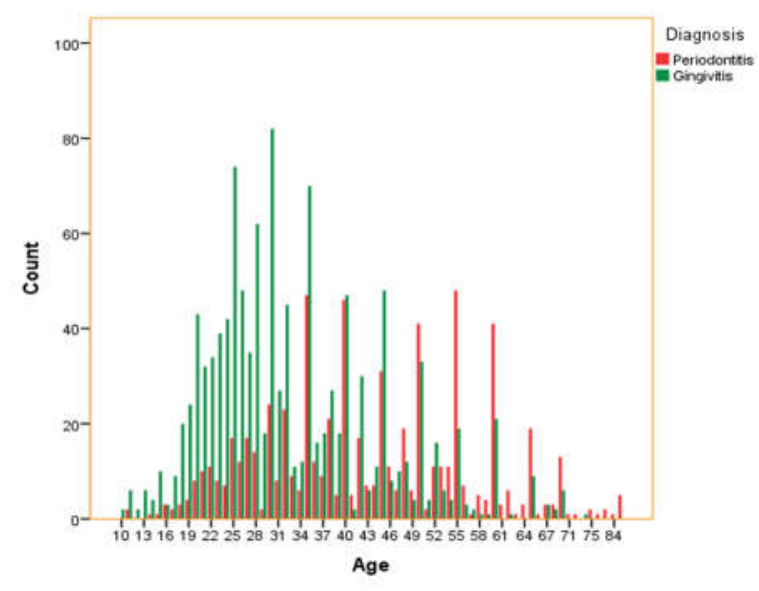

Figure 4: Gender distribution of Periodontal diseases.

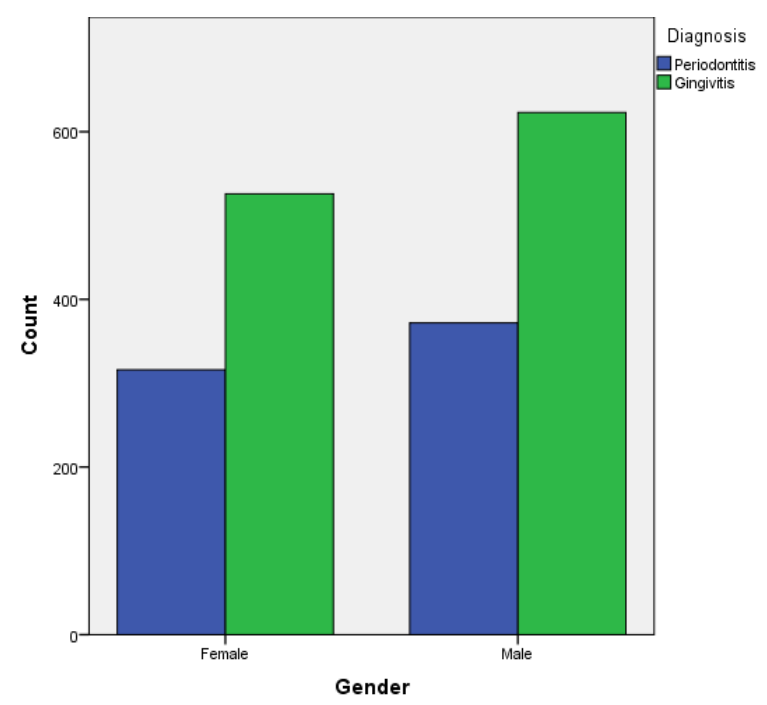

DISCUSSIONS:

The results in this current study indicated that periodontitis generally appeared with in the older age group of both males and females, which support the findings of Sheridan', Albert et al. ${ }^{x i}$, Novaes et al. ${ }^{\text {xiland }}$ Bridges et al. ${ }^{x i i i}$ studies where they showed that periodontal diseases prevalence and severity increases with the advancing patients' age. The results also show that gingivitis was comparatively more experienced before 48 years of age, while periodontitis occurred after 48 years age. All these findings are in consistent with a study by Eke et al. that revealed a high prevalence of periodontitis in US

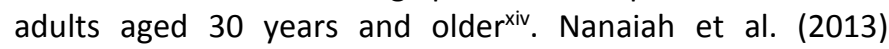
reported that only $1.5 \%$ of 1100 subjects ( $15-18$ years old) had chronic periodontitis, moreover the author confirmed that the gingivitis started to increase in adolescence (16 years old $)^{\mathrm{xv}}$. Bokhari et al. (2015) also stated that subjects aged 40 years and above were four times more likely to suffer from periodontitis ${ }^{\mathrm{xvi}}$. The outcome of the current study confirmed that there is a little impact of gender on distribution of periodontal diseases in this context.

The current study demonstrated that age is possible etiologic factor of change periodontal diseases severity in Dhaka, Bangladesh. This factor should be included in the diagnostic aids, to rule out various types and severity of periodontal diseases. More advanced methods of studies are important to find out other possible etiologic factors for periodontal diseases in this region and to identify the effects of environmental, societal and lifestyle in Bangladesh on periodontal diseases.

\section{CONCLUSION:}

We conclude that periodontal diseases are primarily correlating with the age but gender may not be associated. The most prevalent form of periodontal disease is gingivitis. This study might tell the starting-age of disease initiation and outline of disease progression.

\section{ACKNOWLEDGEMENTS:}

We would like to thank all the intern doctors of Periodontology and Oral Medicine OPD, Update Dental College, Dhaka, Bangladesh for their help and support in the present study in obtaining primary data.

\section{CONFLICTS OF INTEREST}

There are no conflicts of interest. 


\section{REFERENCES:}

i Savage A, Eaton KA, Moles DR, Needlemen I. A Systematic Review of Definitions of Periodontitis and Methods that have been used to Identify This Disease. J Clin Periodontol. 2009;36:458-67.

https://doi.org/10.1111/j.1600-051X.2009.01408.x

PMid:19508246

ii International Workshop for a Classification of Periodontal Diseases and Conditions. Papers. Oak Brook, Illinois, October 30- November 2, 1999. Ann Periodontol. 1999; 4: 1-112.

iii Griffiths, G.S., Wilton, J.M.A., Curtis, M.A., Maiden, M.F.J., Gillett, I.R., Wilson, D.T., et al. (1988) Detection of High-Risk Groups and Individuals for Periodontal Diseases. Clinical Assessment of the Periodontium. Journal of Clinical Periodontology, 15, 403-410.

https://doi.org/10.1111/j.1600-051X.1988.tb01593.x

PMid:3053786

iv Al-Harthi, L.S., Cullinan, M., Leichter, J.W., et al. (2013) Periodontitis among Adult Populations in the Arab World. International Dental Journal , 63, 7-11. https://doi.org/10.1111/idj.12002

PMid:23410016

v Huttner, E.A., Machado, D.C., de Oliveira, R.B., Antunes, A.G. and Hebling, E. (2009) Effects of Humanaging on Periodontal Tissues. Special Care in Dentistry, 29, 149-155.

https://doi.org/10.1111/j.1754-4505.2009.00082.x

PMid:19573041

vi Meisel, P., Reifenberger, J., Haase, R., Nauck, M., Bandt, C. and Kocher, T. (2008) Women Are Periodontally Healthier than Men, but Why Don't They Have More Teeth than Men? Menopause, 15, 270-275.

https://doi.org/10.1097/gme.0b013e31811ece0a

PMid:17917610

vii Mundt, T., Schwahn, C., Mack, F., et al. (2007) Risk Indicators for Missing Teeth in Working-Age Pomeranians-An Evaluation of High-Risk Populations. Journal of Public Health Dentistry , 67, 243-249.

https://doi.org/10.1111/j.1752-7325.2007.00041.x

PMid:18087995

viii Markou, E., Boura, E., Tsalikis, L., Deligianidis, A. and Konstantinidis, A. (2011) The Influence of Sex Hormones on Proinflammatory Cytokines in Gingiva of Periodontally Healthy Premenopausal Women. Journal of Periodontal Research , 46, 528-532.

https://doi.org/10.1111/i.1600-0765.2011.01369.x

PMid:21501171

ix Chandra A, Yadav OP, Narula S, Dutta A. Epidemiology of Periodontal Diseases in Indian Population since Last Decade. J Int Soc Prevent Communit Dent. 2016;6:91-6.

https://doi.org/10.4103/2231-0762.178741

PMid:27114945 PMCid:PMC4820580

xSheridan, P. (1987) Advances in Dental Research. The Journal of the American Dental Association, 115, 741-742.

https://doi.org/10.14219/iada.archive.1987.0293

PMid:3479498

xiAlbert, M., Banoczy, J. and Tamas, G. (1988) Dental and Oral Symptoms of Diabetes Mellitus. Community Dentistry and Oral Epidemiology , 16, 378-380. https://doi.org/10.1111/j.1600-0528.1988.tb00586.x

xiiNovaes, A.B., Pereira, A.L., Moraes, N. and Novaes, A.B. (1991) Manifestations of Insulin Dependent Diabetes Mellitus in the Periodontium of Young Brazilian Patients. https://doi.org/10.1902/jop.1991.62.2.116

PMid:2027059

xiiiBridges, R.B., Anderson, J.W., Saxe, S.R., Gregory, K. and Bridges, S.R. (1996) Periodontal Status of Diabetic and Non-Diabetic Men: Effects of Smoking, Glycemic Control and Socioeconomic Factors. Journal of Periodontology, 67 1185-1192. https://doi.org/10.1902/jop.1996.67.11.1185

PMid:8959568

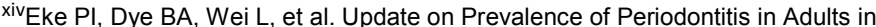
the United States: NHANES 2009-2012. J Periodontol. 2015;86(5):611-22. https://doi.org/10.1902/jop.2015.140520

PMid:25688694 PMCid:PMC4460825

${ }^{x v}$ Nanaiah KP, Nagarathna DV, Manjunath NK. Prevalence of Periodontitis among the Adolescents Aged 15-18 Years in Mangalore City: An epidemiological and microbiological study. J Indian SocPeriodontol. 2013;17(6):784-89. https://doi.org/10.4103/0972-124X.124507

PMid:24554891 PMCid:PMC3917211

xviBokhari SAH, Suhail AM, Malik AR, Imran MF. Periodontal Disease Status and Associated Risk Factors in Patients Attending a Dental Teaching Hospital in Rawalpindi, Pakistan. J Indian SocPeriodontol. 2015;19:678-82. https://doi.org/10.4103/0972-124X.156882

PMid:26941520 PMCid:PMC4753714 